\title{
Prevalence of chronic kidney disease in Nigeria: systematic review of population-based studies
}

This article was published in the following Dove Press journal: International Journal of Nephrology and Renovascular Disease

\section{Innocent ljezie \\ Chukwuonye' \\ Okechukwu Samuel Ogah ${ }^{2}$ \\ Ernest Ndukaife Anyabolu ${ }^{3}$ \\ Kenneth Arinze Ohagwu' \\ Ogbonna Collins Nwabuko ${ }^{4}$ \\ Uwa Onwuchekwa ${ }^{5}$ \\ Miracle Erinma \\ Chukwuonye ${ }^{6}$ \\ Emmanuel Chukwuebuka \\ Obi' \\ Efosa Oviasu ${ }^{7}$ \\ 'Division of Nephrology, Department of Internal Medicine, Federal Medical Centre, Umuahia, Abia State, ${ }^{2}$ Division of Cardiology, Department of Internal Medicine, University College Hospital Ibadan, Oyo State ${ }^{3}$ Division of Nephrology, Department of Internal Medicine, Chukwuemeka Odumegwu Ojukwu University Teaching Hospital Awka, Anambra State, ${ }^{4}$ Department of Haematology, Federal Medical Centre, Umuahia, ${ }^{5}$ Division of Nephrology, Department of Internal Medicine, Abia State University Teaching Hospital, Aba, ${ }^{6}$ Department of Family Medicine, Federal Medical Centre, Umuahia, ${ }^{7}$ Division of Nephrology, Department of Internal Medicine, University of Benin Teaching Hospital, Benin City, Nigeria}

Correspondence: Innocent ljezie Chukwuonye

Division of Nephrology, Department of Internal Medicine, Federal Medical Centre, PO Box 1229 Umuahia Branch Office, Umuahia, Nigeria

Tel +2348038774307

Email chukwuonye4@yahoo.com
Background: The aim of this study was to identify and discuss published population-based studies carried out in Nigeria that have information on the prevalence of chronic kidney disease (CKD) and have also used the Kidney Disease Outcomes Quality Initiative (KDOQI) practice guidelines in defining $\mathrm{CKD}$, with emphasis on the performance of three estimating equations for glomerular filtration rate (GFR) - Modification of Diet in Renal Disease (MDRD), Cockcroft-Gault, and CKD epidemiology collaboration (CKD-EPI) creatinine equation.

Materials and methods: A systematic literature search was carried out in Google, MEDLINE, PubMed, and AJOL database, with the aim of identifying relevant population-based studies with information on the prevalence of CKD in a location in Nigeria.

Results: Seven cross-sectional population-based studies were identified. Two of the studies used the Cockcroft-Gault and observed a prevalence of $24.4 \%$ and $26 \%$. Four of the studies used the MDRD and the prevalences observed were $12.3 \%, 14.2 \%, 2.5 \%$, and $13.4 \%$. One of the studies used the CKD-EPI equation and the prevalence was $11.4 \%$. The male to female ratios of CKD prevalence in six studies were 1:1.9, 0.8:1, 1:1.6, 1:2, 1:1.8, 1:1.4, and the observed risk factors in the studies were old age, obesity, diabetes mellitus, hypertension, family history of hypertension, family history of renal disease, low-income occupation, use of traditional medication, low hemoglobin, and abdominal obesity.

Conclusion: The prevalence of CKD was high but variable in Nigeria, influenced by the equation used to estimate the GFR. MDRD and CKD-EPI results are agreeable. There is a need for more population-based studies, with emphasis on repeating the GFR estimation after 3 months in subjects with GFR $<60 \mathrm{~mL} / \mathrm{min} / 1.7 \mathrm{~m}^{2}$.

Keywords: CKD, Cockcroft-Gault, Modification of Diet in Renal Disease, CKD epidemiology collaboration creatinine equation

\section{Introduction}

Chronic kidney disease (CKD) is defined as kidney damage or glomerular filtration rate $(\mathrm{GFR})<60 \mathrm{~mL} / \mathrm{min} / 1.73 \mathrm{~m}^{2}$ for $\geq 3$ months. ${ }^{1} \mathrm{CKD}$ is a worldwide public health problem, with adverse outcomes of kidney failure, cardiovascular disease, and premature death. ${ }^{1}$ Presently, there is an increase in the prevalence of CKD. It was ranked 27 th in the list of causes of total number of global deaths in 1990; however, by 2010, it had dropped to 18th in the list of causes of global deaths. This degree of movement up the list was noted to be second only to that of HIV and AIDS. ${ }^{2}$ About $10 \%$ of the world's population is affected by $\mathrm{CKD} .^{3}$

Hypertension and diabetes mellitus (chronic non-communicable diseases [NCDs]) are the two major causes of CKD worldwide. However, chronic glomerulonephritis 
and interstitial nephritis are the major causes of CKD in developing countries of the world. This is a reflection of the high prevalence of bacterial, parasitic, and viral infections (communicable diseases) that affect the kidneys in these countries. ${ }^{4}$ The prevalence of $\mathrm{CKD}$ is also increasing at a more rapid rate in developing countries. These differences between the developed and the developing countries are due to the fact that the burden of CKD is moving away from communicable diseases and toward chronic NCDs in the developed countries of the world. However, in developing countries, there is a double burden of communicable diseases and NCDs. The prevalence of some diseases such as obesity, hypertension, and diabetes mellitus has increased in the developing countries of the world such as Nigeria due to many factors. ${ }^{4-6}$

The attention being paid globally to CKD is attributable to five factors: the rapid increase in its prevalence, the enormous cost of treatment, recent data indicating that overt disease is the tip of an iceberg of covert disease, an appreciation of its major role in increasing the risk of cardiovascular disease, and the discovery of effective measures to prevent its progression. ${ }^{4}$

CKD has a huge financial burden on families of subjects with the medical condition in Nigeria ${ }^{7,8}$ and in order to drastically reduce the frequency of CKD in the country, a good knowledge of its prevalence is needed and such knowledge can only be obtained from population-based epidemiologic studies. There are several studies on CKD in Nigeria. ${ }^{9-11}$ However, most of these studies are hospital based. This study reviews only published population-based studies that have information on the prevalence of CKD in Nigeria, and that also used the Kidney Disease Outcomes Quality Initiative (KDOQI) practice guidelines in defining CKD with emphasis on the performance of three estimating equations for GFR - the Modification of Diet in Renal Disease (MDRD), Cockcroft-Gault (CG), and CKD epidemiology collaboration (CKD-EPI) creatinine equation.

\section{Materials and methods}

\section{Selection of eligible studies, types of studies, and sources of information}

A systematic literature search was conducted in Google and MEDLINE database to identify all publications on CKD in Nigeria with the aim to sieve out population-based studies with relevant information on the prevalence of CKD in locations in Nigeria published before 1 November, 2017 (search limit). The systematic review was carried out in the last quarter of 2017. The search terms used in Google and MEDLINE database were "chronic kidney disease in
Nigeria" or "chronic renal failure in Nigeria". In addition, some full articles of identified community-based studies that we had difficulty obtaining were also searched for in PubMed and the African Journals Online using the title of the article or the name of the first author.

\section{Search strategy}

The articles are published in English language, the official language of Nigeria. In order to eliminate difficulties in analyzing the data, attention was paid to population-based studies that made use of the same definition of CKD.

\section{Inclusion criteria}

1. The study is population based with relevant information on the prevalence of CKD in a location in Nigeria.

2. $\mathrm{CKD}$ is defined as estimated GFR $<60 \mathrm{~mL} / \mathrm{min}$ by the $\mathrm{CG}$ formula, or an estimated GFR of $<60 \mathrm{~mL} / \mathrm{min} / 1.73$ $\mathrm{m}^{2}$ by the MDRD and CKD-EPI creatinine equation. This definition is in keeping with the K/DOQI practice guidelines published in 2002 by the National Kidney Foundation. $^{12}$

3. The study involves adult Nigerians of both male and female gender.

4. There is a representative sample of the general population in the study.

5. The MDRD, CG, or the CKD epidemiology equation was used to estimate the GFR in the study.

6. The study has a full publication, and is not published only in abstract.

\section{Exclusion criteria}

Studies that did not meet the inclusion criteria were excluded from this review. Population-based studies limited to a particular profession or patients with a particular disease condition (e.g., civil servants, HIV, university community) were excluded.

\section{Definition of terms}

\section{Chronic kidney disease}

This is defined as creatinine clearance or GFR $<60 \mathrm{~mL} /$ $\min / 1.73 \mathrm{~m}^{2} .^{12}$

\section{Cockcroft-Gault}

Creatinine clearance $(\mathrm{mL} / \mathrm{min})=(140-$ age $) /($ serum creatinine $) \times($ weight $/ 72) \times(0.85 \text { if female })^{13}$

Serum creatinine is measured in $\mathrm{mg} / \mathrm{dL}$, age in years, weight in $\mathrm{kg}$, and GFR is expressed as $\mathrm{mL} / \mathrm{min}$. 


\section{Simplified (four-variable) MDRD equation}

GFR $\left(\mathrm{mL} / \mathrm{min} / 1.73 \mathrm{~m}^{2}\right)=186.3 \times($ serum creatinine $)-1.154 \times$ (age) $-0.203 \times(0.742$ if female $) \times(1.21 \text { if black })^{14}$

Serum creatinine is measured in $\mathrm{mg} / \mathrm{dL}$, age in years, and GFR is expressed as $\mathrm{mL} / \mathrm{min} / 1.73 \mathrm{~m}^{2}$.

\section{CKD-EPI formula}

GFR $=141 \times \min (\mathrm{Scr} / \kappa, 1) \alpha \times \max (\mathrm{Scr} / \kappa, 1)-1.209 \times 0.993$ age $\times 1.018$ (if female) $\times 1.159$ (if black) $)^{15}$

where Scr is serum creatinine in $\mathrm{mg} / \mathrm{dL}, \kappa$ is 0.7 for females and 0.9 for males, $\alpha$ is -0.329 for females and -0.411 for males, min indicates the minimum of $\mathrm{Scr} / \mathrm{K}$ or 1 , and $\max$ indicates the maximum of $\mathrm{Scr} / \kappa$ or 1 .

GFR is expressed as $\mathrm{mL} / \mathrm{min} / 1.73 \mathrm{~m}^{2}$.

\section{Data collection}

All identified articles from the search were downloaded, and hospital-based studies were jettisoned from the study. The full-text versions of all community-based studies on CKD were obtained, and the articles that did not meet the inclusion criteria were excluded.

\section{Data extraction}

The community-based studies that met the inclusion criteria were closely scrutinized by at least two authors and the relevant data extracted. Any controversy surrounding any article was collectively resolved by all authors giving their opinion and the final decision taken by consensus. The data extracted from studies that met the inclusion criteria included the location of the study in Nigeria, the year of the study, sample size, mean age of subjects, sampling method, GFR equation/formula used, prevalence of CKD, and the male:female ratio of prevalence of CKD. Other data extracted from each of the studies included prevalence of $\mathrm{CKD}$ by age and risk factors of CKD (in studies that carried out multiple logistic regression). These data were computed into tables to allow for easy comparison.

\section{Results}

The search on population-based studies that had relevant information on the prevalence of CKD in Nigeria returned a total of 65 articles. Sixteen of these articles were populationbased studies. Seven of the population-based studies met the inclusion criteria. ${ }^{16-22}$ Each of the seven articles was closely scrutinized by at least two authors. Any controversy surrounding any particular article was discussed by all the authors, and a collective decision taken on the article (Figure 1).

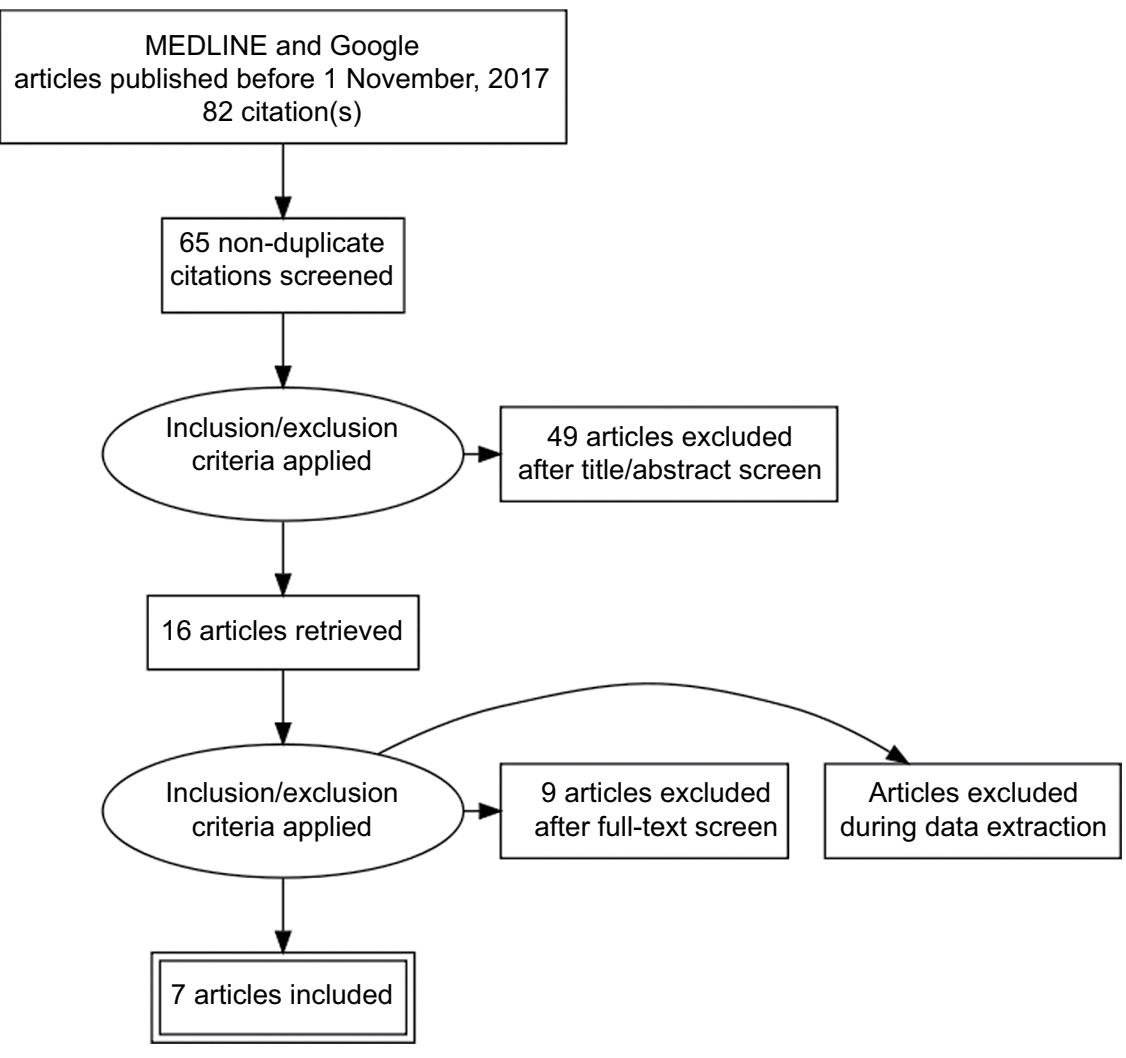

Figure I PRISMA flow diagram of studies.

Abbreviation: PRISMA, preferred reporting items for systematic reviews and meta-analysis. 
One of the seven articles was from South-south zone, ${ }^{16}$ two from South-west, ${ }^{17,20}$ two South-east, ${ }^{18,22}$ one from Northwest, ${ }^{19}$ one from the North-central, ${ }^{21}$ and none was from the North-east geopolitical zone of Nigeria (Figure 2). The subjects who took part in the studies were males and females of age $\geq 18$ years. The mean age in the studies ranged from $39.0 \pm 11.0^{21}$ to $54.8 \pm 12.8$ years. $^{22}$ There was no particular study that focused on a particular age group (e.g., elderly subjects). The least sample size was $328^{22}$ and the largest sample size was $1941^{18}$ (Table 1).

All the seven relevant studies were cross-sectional. One of the studies used cluster sampling method, ${ }^{16}$ three studies used multistage sampling technique, ${ }^{17,19,22}$ two other studies used convenience sampling technique, ${ }^{18,21}$ and one of the studies ${ }^{20}$ did not state what sampling method was used.
Two of the studies used the CG formula in estimating GFR, ${ }^{16,19}$ four studies used the MDRD, ${ }^{17,20-22}$ whereas one of the studies used the CKD-EPI creatinine equation. ${ }^{18}$ The prevalence of CKD from two of the studies that used the CG formula was very high when compared to those obtained with the MDRD and the CKD-EPI creatinine equations. Three of the studies that used the MDRD equation ${ }^{17,20,22}$ and the only study that used the CKD-EPI creatinine equation ${ }^{18}$ had similar results. However, one of the studies that used the $\mathrm{MDRD}^{21}$ has a very low prevalence of CKD when compared to the other three results.

Six out of the seven studies provided a gender-specific prevalence of CKD, and the prevalence of CKD was greater in females in all the six studies (this is expressed in a ratio format in Table 1). ${ }^{16,17,19-22}$

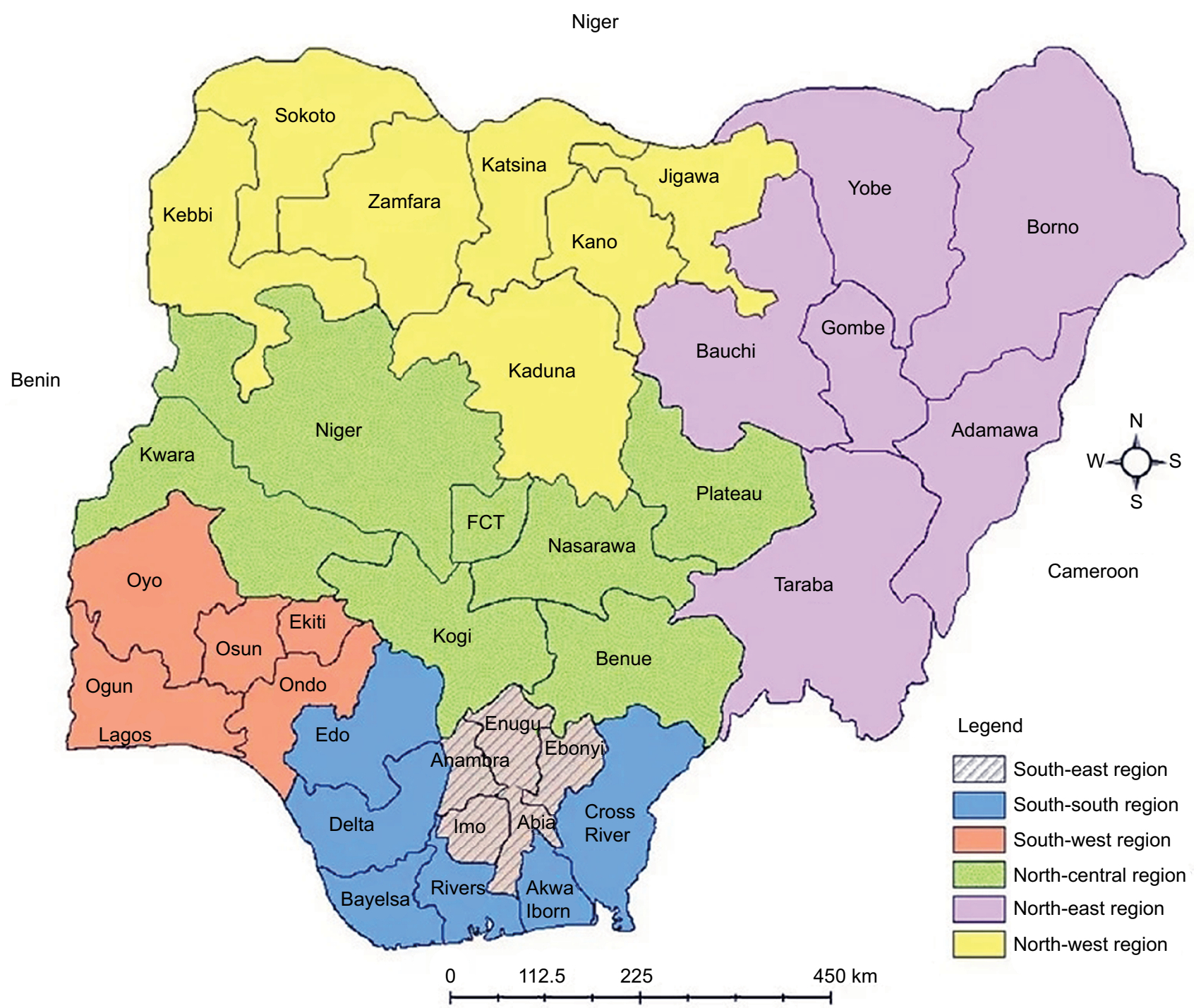

Figure 2 Map of Nigeria showing the six geopolitical zones. Abbreviation: FCT, Federal Capital Territory. 
Table I Prevalence of chronic kidney disease from population-based studies in Nigeria

\begin{tabular}{|c|c|c|c|c|c|c|c|c|}
\hline Reference & Location in Nigeria/state & $\begin{array}{l}\text { Year of } \\
\text { study }\end{array}$ & $\begin{array}{l}\text { Sample } \\
\text { size }\end{array}$ & $\begin{array}{l}\text { Mean age } \\
\text { (years) }\end{array}$ & $\begin{array}{l}\text { Sampling } \\
\text { method }\end{array}$ & $\begin{array}{l}\text { GFR } \\
\text { equation }\end{array}$ & $\begin{array}{l}\text { Prevalence } \\
\text { of CKD (\%) }\end{array}$ & $\begin{array}{l}\text { Prevalence } \\
\text { of CKD M:F }\end{array}$ \\
\hline 16 & Etsako/Edo & 2009 & 520 & & Cluster & CG & 24.3 & $1: 1.9$ \\
\hline 17 & Ilie, Olorunda/Osun & 2008 & 454 & $45.8 \pm 19.0$ & Multistage & MDRD & 12.3 & $0.8: 1$ \\
\hline 18 & $\begin{array}{l}\text { Enugu (Ujodo Nike, Emene-Nike } \\
\text { and Mbulu-Ujodo)/Enugu }\end{array}$ & 2013 & |94| & $43.7 \pm 13.2$ & Convenience & CKD-EPI & $1 \mathrm{I} .4$ & \\
\hline 19 & Kumbotso/Kano & & 450 & $39.6 \pm 16.4$ & Multistage & CG & 26 & 1:1.6 \\
\hline 20 & $\begin{array}{l}\text { Ten communities from Ekiti } \\
\text { North and Central senatorial } \\
\text { districts/Ekiti }\end{array}$ & 2013 & 1084 & $56.3 \pm 19.9$ & & MDRD & 14.2 & $1: 2$ \\
\hline 21 & Jos/Plateau & 2013 & 510 & $39.0 \pm 11.0$ & Convenience & MDRD & 2.5 & $1: 1.8$ \\
\hline 22 & Umuahia (Olokoro)/Abia & 2014 & 328 & $54.8 \pm 12.8$ & Multistage & MDRD & 13.4 & I:I.4 \\
\hline
\end{tabular}

Notes: Each of the seven studies included men and women, and CKD was defined as GFR $<60 \mathrm{~mL} / \mathrm{min} / 1.73 \mathrm{~m}^{2}$.

Abbreviations: CG, Cockcroft-Gault; CKD, chronic kidney disease; CKD-EPI, chronic kidney disease epidemiology collaboration; F, female; GFR, glomerular filtration rate; M, male; MDRD, Modification of Diet in Renal Disease.

Table 2 Distribution of prevalence of CKD among the various stratified age groups and the risk factors of CKD

\begin{tabular}{|c|c|c|}
\hline References & $\begin{array}{l}\text { Prevalence of } \\
\text { CKD by age (\%) }\end{array}$ & $\begin{array}{l}\text { Risk factors for CKD } \\
\text { (multiple logistic regression) }\end{array}$ \\
\hline \multirow[t]{2}{*}{16} & & Age $\geq 50$ years \\
\hline & & Obesity ( $\uparrow$ BMI $\geq 30)$ \\
\hline \multirow[t]{3}{*}{17} & & Female gender \\
\hline & & Systolic blood pressure \\
\hline & & Diabetes \\
\hline \multirow[t]{4}{*}{18} & & Older age \\
\hline & & Low-income occupation \\
\hline & & Use of traditional medication \\
\hline & & Low hemoglobin \\
\hline \multirow[t]{4}{*}{19} & $18-29$ years -20.2 & Obesity $(\uparrow B M I \geq 30)$ \\
\hline & $30-44$ years -20.9 & Family history of hypertension \\
\hline & $45-60$ years -30.6 & History of diabetes mellitus \\
\hline & $6 I-90$ years -42.9 & Family history of renal disease \\
\hline \multicolumn{3}{|r|}{ 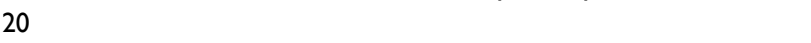 } \\
\hline 21 & & Age \\
\hline \multirow[t]{5}{*}{22} & & Old age \\
\hline & & Hypertension \\
\hline & & Family history of kidney disease \\
\hline & & Obesity $(\mathrm{BMI} \geq 30)$ \\
\hline & & Central obesity \\
\hline
\end{tabular}

Abbreviations: BMI, body mass index; CKD, chronic kidney disease.

One of the studies stratified the prevalence of CKD based on age. ${ }^{19}$ The prevalence of CKD increased steadily with age in this study population (Table 2).

Univariate binary logistic analysis was used in six studies $^{16-19,21,22}$ to determine the relationship between CKD and various variables. This was followed by multiple logistic regression using the variables from the univariate binary logistic analysis that were significantly associated with CKD, in order to determine the predictors (risk factors) of CKD (Table 2). The most common risk factor among the studies was old age, ${ }^{16,18,21,22}$ followed by obesity ( $\uparrow$ body mass index $\left.\geq 30 \mathrm{~kg} / \mathrm{m}^{2}\right) ;{ }^{16,19,22}$ others were diabetes mellitus, ${ }^{17,18}$ hypertension, ${ }^{17,22}$ family history of hypertension, ${ }^{19,22}$ and family history of renal disease. ${ }^{19,22}$ Less common risk factors included low-income occupation, use of traditional medications, low hemoglobin, and central obesity. ${ }^{18,22}$

\section{Discussion}

The prevalences of CKD observed from the seven populationbased cross-sectional studies that met the inclusion criteria were $24.3 \%,{ }^{16} 12.3 \%,{ }^{17} 11.4 \%,{ }^{18} 26 \%,{ }^{19} 14.2 \%,{ }^{20} 2.5 \%,{ }^{21}$ and $13.4 \%{ }^{22}$ The prevalences of CKD in the two studies that used the CG to estimate the GFR were $24.3 \%{ }^{16}$ and $26 \% .{ }^{19}$ These values were much higher than those obtained with the four studies that used the MDRD $\left(12.3 \%,{ }^{17} 14.2 \%,{ }^{20} 2.5 \%,{ }^{21}\right.$ and $13.4 \%{ }^{22}$ ) and the only study that used the CKD-EPI ${ }^{18}$ creatinine equation (11.4\%). The prevalences observed in three of the MDRD equations $\left(12.3 \%,{ }^{17} 14.2 \%,{ }^{20} 13.4 \%{ }^{22}\right)$ and that observed in the CKD-EPI creatinine equation $\left(11.4 \%{ }^{18}\right)$ were within reasonable agreement. These results suggest that the prevalence of CKD depends on the equation used to estimate GFR and further showed that the CG gives a lower estimate of GFR than the MDRD and the CKD-EPI creatinine equations. Similar observation was made by Viktorsdottir et $\mathrm{al}^{23}$ in a study in which 19,381 subjects participated. The study revealed that GFR estimates and the prevalence of CKD are dependent on the equation used to calculate estimated GFR. The study compared three different equations used to calculate estimated GFR based on serum creatinine and to estimate the prevalence of CKD in the Icelandic population. It was observed that the GFRs estimated by the three equations used in the study were different. CG gave lower values 
of estimated GFR when compared to MDRD. Chen et $\mathrm{a}^{24}$ in a study that evaluated the prevalence of decreased kidney function in Chinese adults aged 35-74 years observed that the prevalence of moderately and severely decreased kidney function estimated using the CG equation was much higher than that estimated using the four variable MDRD study equations in a Chinese population. Using CG, the prevalences of GFR $30-59 \mathrm{~mL} / \mathrm{min} / 1.73 \mathrm{~m}^{2}$ and GFR $<30 \mathrm{~mL} / \mathrm{min} / 1.73$ $\mathrm{m}^{2}$ were $19.6 \%$ and $0.8 \%$, respectively, while for MDRD, the prevalences of estimated GFR of $30-59 \mathrm{~mL} / \mathrm{min} / 1.73$ $\mathrm{m}^{2}$ and GFR $<30 \mathrm{~mL} / \mathrm{min} / 1.73 \mathrm{~m}^{2}$ were $2.4 \%$ and $0.14 \%$, respectively. However, for mildly decreased GFR (60-90 $\mathrm{mL} / \mathrm{min} / 1.73 \mathrm{~m}^{2}$ ), the same prevalence value $(39.4 \%$ ) was observed with both equations.

Matsha et $\mathrm{al}^{25}$ assessed the prevalence and determinants of CKD and evaluated the concordance of commonly advocated estimators of GFR in a mixed ancestry population from South Africa in their study comprising 1202 subjects. The estimated GFR was based on the CG, MDRD, and CKD-EPI equations (with and without adjustment for ethnicity). The crude prevalence of CKD stage 3-5 was $14.8 \%$ for CG, $7.6 \%$ and $23.9 \%$ for MDRD with and without ethnicity correction, respectively, and $7.4 \%$ and $17.3 \%$ for the CKD-EPI creatinine equations with and without ethnicity correction, respectively. The highest agreement between GFR estimators was between MDRD and CKD-EPI equations, both with ethnicity correction..$^{25}$ There are controversies over which one of these popular equations is more reliable in patients with GFR $<60 \mathrm{~mL} / \mathrm{min} / 1.73 \mathrm{~m}^{2}$. Evans et $\mathrm{al}^{26}$ compared the performance of five different estimated GFR equations, CG, MDRD, CKD-EPI, Mayo Clinic, and Lund-Malmö, with measured GFR (plasma iohexol clearance) in 2098 referred CKD patients with advanced renal failure. The GFR-estimating equations showed reasonably good performance at the population level. The best overall performance was achieved by Lund-Malmö and CKD-EPI equations, followed by the MDRD. The performance of MDRD was much better than that of CG. The performance of MDRD was almost the same as the CKD-EPI equation. ${ }^{26}$ However, this study was carried out in a Caucasian population. The high agreement between the GFR estimation by the four-variable MDRD and the CKD-EPI creatinine equation is due to the fact that the CKD-EPI creatinine equation is based on the same four variables as the MDRD study equation, the only difference being that it uses a twoslope spline to model the relationship between estimated GFR and serum creatinine and a different relationship for race, age and gender. ${ }^{15}$
Four of the studies in this review used the MDRD equation for GFR estimation. ${ }^{17,20-22}$ However, one of the studies ${ }^{21}$ observed a very low prevalence when compared to the other three. The study was carried out in Jos in the North-central region of Nigeria. The very low prevalence observed in the study tends to suggest that the prevalence of CKD is low in that region. However, this is not an assumption. It is most likely that the low prevalence observed in the study is due to the study method used - convenience sampling method. The convenience sampling method does not require the generation of a simple random sample; the only requirement is usually the availability of participants who have agreed to participate. It is more likely that a sample will resemble the population when the method used to select the sample utilizes a random process. The convenience sampling method is characterized by insufficient power to identify the differences in population subgroups. The results of convenience sampling method cannot be generalized to the target population because of the potential bias of the sampling technique. Inferences on a study based on convenience sampling method are made about the sample itself. ${ }^{27,28}$

One other study that used the MDRD creatinine equation did not state the sampling method used in the study. ${ }^{20}$ However, the fact that 10 communities were chosen by a random process from two senatorial districts in Ekiti state, and that the study period was 6 months, clearly shows that convenience sampling method was not the sampling method used. It is most likely that the method that was used was either cluster or stratified random or multistage, like in their earlier study in Osun state. ${ }^{17}$ The study seems to have also used the CKD-EPI creatinine equation in estimating the GFR. This is implied in the article. However, only the result of the MDRD equation was reported in the article.

The only study that used the CKD-EPI creatinine equation $^{18}$ used a hybrid of a random sampling method and convenience sampling method. The initial sampling method was a random process (two semi-urban and two rural communities selected by a random process). However, due to the age distribution of the populations, that is, younger population in semi-urban areas and older population in rural communities, the study ultimately used a convenience sampling strategy. ${ }^{18}$

The male to female ratios (M:F) of the prevalence of CKD in six of the studies were $1: 1.9,{ }^{16} 0.8: 1,{ }^{17} 1: 1.6,{ }^{19} 1: 2,{ }^{21}$ $1: 1.8,{ }^{21}$ and $1: 1.4,{ }^{22}$ respectively. The studies presented a gender-specific prevalence of CKD, with the prevalence being higher in the female gender. Zhang and Rothenbacher ${ }^{12}$ in a review of population-based studies on the prevalence of 
CKD observed that several studies had higher prevalence of CKD in females. Kalyesubula et $\mathrm{al}^{29}$ in a community-based study on kidney disease in Uganda also recorded a higher prevalence of CKD in the female gender. The fact that men have more muscle mass than women, and the differences in hormone metabolism and glomerular structure are assumed to play a role in the differences in prevalence of CKD observed between male and female gender. ${ }^{30}$

Only one study stratified the prevalence of CKD based on age. ${ }^{19}$ The prevalence of CKD increased steadily with age in the study population. van Blijderveen et $\mathrm{al}^{31}$ in a retrospective cohort study conducted in a dynamic population using data of 784,563 adult participants also observed that the incidence/ prevalence of CKD increases steadily with age. Several other previous population-based studies also observed a steady increase in the prevalence of CKD with age. ${ }^{12}$

Six of the studies ${ }^{16-19,21,22}$ used binary/multiple regressions to determine the risk factors of CKD in their location/region in Nigeria. Old age, ${ }^{16,18,21,22}$ obesity (body mass index $\geq 30 \mathrm{~kg}$ / $\left.\mathrm{m}^{2}\right),{ }^{16,19,22}$ diabetes mellitus, ${ }^{17,18}$ hypertension, ${ }^{17,22}$ family history of hypertension, ${ }^{19,22}$ family history of renal disease, ${ }^{19,22}$ low-income occupation, ${ }^{18}$ use of traditional medication, ${ }^{18}$ low hemoglobin, ${ }^{18}$ and central obesity ${ }^{22}$ were found to be the risk factors of CKD. The observed risk factors did not include any communicable diseases because communicable diseases were not included in the binary/multiple regressions. However, studies from other African nations show that communicable diseases are risk factors of CKD in sub-Saharan African countries. ${ }^{32}$

\section{Limitations of the studies}

A major drawback in these studies is that the estimated GFR of the subjects who were observed to have CKD was only assessed once. Ideally, the assessments should have been repeated 3 months later to find out if the values of the estimated GFR were still below $60 \mathrm{~mL} / \mathrm{min} / 1.73 \mathrm{~m}^{2}$ in the subjects with CKD. ${ }^{1}$ This would have given an accurate prevalence of CKD with creatinine equations. It is worth noting that one of the studies did repeat the GFR estimation 3 months later; estimated GFR $<60 \mathrm{~mL} / \mathrm{min} / 1.73 \mathrm{~m}^{2}$ was found in $44(13.4 \%)$ participants at the first assessment and only 15 participants (4.6\%) had persistently low GFR at reassessment 3 months later. ${ }^{22}$ The sharp drop in the prevalence clearly shows that a good majority of the earlier captured subjects did not have CKD. A major limitation of the study that repeated the estimation of GFR 3 months later is that the sample size was small (328), and the value obtained is not likely to be the true prevalence of CKD in Nigeria. However, the prevalence of CKD is most likely to be below $10 \%$ and may be close to $4.6 \%$ using the MDRD and CKD-EPI creatinine equation.

\section{Conclusion}

There was variable prevalence of CKD in the studies, influenced by the creatinine equation used to estimate the GFR. The MDRD and CKD-EPI results are agreeable, and they are better than the $\mathrm{CG}$ creatinine formula in estimating the GFR in subjects with GFR $<60 \mathrm{~mL} / \mathrm{min} / 1.7 \mathrm{~m}^{2}$. Discordantly high CKD prevalence at the first test and low value at 3 months interval in one of the studies demonstrated that high prevalence values were obtained in estimating the GFR once and not repeating the test 3 months later.

\section{Recommendation}

We recommend more cross-sectional, large sample size, population-based studies on the prevalence of CKD, using multistage sampling method, with emphasis on repeating the GFR estimation 3 months later. These will provide the true prevalence of CKD using the popular creatinine equations (preferably MDRD or CKD-EPI creatinine equation).

\section{Disclosure}

The authors report no conflicts of interest in this work.

\section{References}

1. Levey AS, Atkins R, Coresh J, et al. Chronic kidney disease as a global public health problem: approaches and initiatives - a position statement from Kidney Disease Improving Global Outcomes. Kidney Int. 2007;72(3):247-259.

2. Jha V, Garcia-Garcia G, Iseki K, et al. Chronic kidney disease: global dimension and perspectives. Lancet. 2013;382(9888):260-272.

3. World Kidney Day: Chronic Kidney Disease; 2015. Available from: http://www.worldkidneyday.org/faqs/chronic-kidney-disease/.Accessed December 10, 2017.

4. Barsoum RS. Chronic kidney disease in the developing world. $N$ Engl J Med. 2006;354(10):997-999.

5. Okpechi IG, Chukwuonye II, Tiffin N, et al. Blood pressure gradients and cardiovascular risk factors in Urban and rural populations in Abia State South Eastern Nigeria using the WHO STEPwise approach. PLoS One. 2013;8(9):e73403.

6. Chukwuonye II, Chuku A, John C, et al. Prevalence of overweight and obesity in adult Nigerians - a systematic review. Diabetes Metab Syndr Obes. 2013;6:43-47.

7. Chukwuonye II, Oviasu E. The plight of chronic kidney disease patients in Nigeria. J Dental Med Sci. 2012;2(2):52-55.

8. Ulasi II, Ijoma CK. The enormity of chronic kidney disease in Nigeria: the situation in a teaching hospital in South-east Nigeria. J Trop Med. 2010;2010:501957.

9. Egbi OG, Unuigbe E, Oviasu E. Prevalence of chronic kidney disease in patients with metabolic syndrome: a single-center experience in Nigeria. Afr J Nephrol. 2014;17(1):28-34. 
10. Anyabolu EN, Chukwuonye II, Arodiwe E, Ijoma CK, Ulasi I. Prevalence and predictors of chronic kidney disease in newly diagnosed human immunodeficiency virus patients in Owerri, Nigeria. Indian $J$ Nephrol. 2016;26(1):10-15.

11. Olokor AB, Ojogwu IL, Ugbodaga PF. Hyperhomocysteinemia in chronic kidney disease patients in a teaching hospital in Nigeria. $\mathrm{Br} J$ Med Med Res. 2016;18(9):1-7.

12. Zhang QL, Rothenbacher D. Prevalence of chronic kidney disease in population-based studies: systematic review. BMC Public Health. 2008;8:117.

13. Cockcroft DW, Gault MH. Prediction of creatinine clearance from serum creatinine. Nephron. 1976;16(1):31-41.

14. Levey AS, Bosch JP, Lewis JB, Greene T, Rogers N, Roth D. A more accurate method to estimate glomerular filtration rate from serum creatinine: a new prediction equation. Modification of Diet in Renal Disease Study Group. Ann Intern Med. 1999;130(6):461-470.

15. Levey AS, Stevens LA, Schmid CH, et al; CKD-EPI (Chronic Kidney Disease Epidemiology Collaboration). A new equation to estimate glomerular filtration rate. Ann Intern Med. 2009;150(9):604-612.

16. Okoye O, Okoye A, Oviasu E. Ojogwu L. Prevalence of chronic kidney disease and its risk factors amongst adults in a rural population in Edo State, Nigeria. J US China Med Sci. 2011;8(8):471-481.

17. Oluyombo R, Ayodele OE, Akinwusi PO, et al. A community study of the prevalence, risk factors and pattern of chronic kidney disease in Osun State, South West Nigeria. West Afr J Med. 2013;32(2):85-92.

18. Ulasi II, Ijoma CK, Onodugo OO, Arodiwe EB, Ifebunandu NA, Okoye JU. Towards prevention of chronic kidney disease in Nigeria: a community-based study in Southeast Nigeria. Kidney Int Suppl. 2013;3(2):195-201.

19. Nalado A, Abdu A, Adanu B, et al. Prevalence of chronic kidney disease markers in Kumbotso rural Northen Nigeria. Afr J Med Sci. 2016;45(1):61-65.

20. Oluyombo R, Olamoyegun MA, Ayodele OE, Akinwusi PO, Akinsola A. Clustering of chronic kidney disease and cardiovascular risk factors in South-west Nigeria. J Nephropathol. 2017;6(3):196-203.

21. Abene EE, Gimba ZM, Agaba PA, et al. Chronic kidney disease screening: results of the 2013 world kidney day activities conducted at the Jos University Teaching Hospital. Highland Med Res J. 2017;17(1):1-5.
22. Okwuonu CG, Chukwuonye II, Adejumo OA, Agaba EI, Ojogwu LI. Prevalence of chronic kidney disease and its risk factors among adults in a semi-urban community of South-east Nigeria. Niger Postgrad Med J. 2017;24(2):81-87.

23. Viktorsdottir O, Palsson R, Andresdottir MB, Aspelund T, Gudnason V, Indridason OS. Prevalence of chronic kidney disease based on estimated glomerular filtration rate and proteinuria in Icelandic adults. Nephrol Dial Transplant. 2005;20(9):1799-1807.

24. Chen J, Wildman RP, Gu D, et al. Prevalence of decreased kidney function in Chinese adults aged 35 to 74 years. Kidney Int. 2005;68(6):2837-2845.

25. Matsha TE, Yako YY, Rensburg MA, Hassan MS, Kengne AP, Erasmus RT. Chronic kidney diseases in mixed ancestry south African populations: prevalence, determinants and concordance between kidney function estimators. BMC Nephrol. 2013;14:75.

26. Evans M, Stralen KJ, Schön S, et al; ERA-EDTA Registry; Swedish Renal Registry Collaboration. Glomerular filtration rate-estimating equations for patients with advanced chronic kidney disease. Nephrol Dial Transplant. 2013;28(10):2518-2526.

27. Palinkas LA, Horwitz SM, Green CA, Wisdom JP, Duan N, Hoagwood $\mathrm{K}$. Purposeful sampling for qualitative data collection and analysis in mixed method implementation research. Adm Policy Ment Health. 2015;42(5):533-544.

28. Bornstein MH, Jager J, Putnick DL. Sampling in developmental science: situations, shortcomings, solutions, and standards. Dev Rev. 2013;33(4):357-370.

29. Kalyesubula R, Nankabirwa JI, Ssinabulya I, et al. Kidney disease in Uganda: a community-based study. BMC Nephrol. 2017;18(1):116.

30. Hecking M, Bieber BA, Ethier J, et al. Sex specific differences in hemodialysis prevalence and practices and the male to - female mortality rate: the Dialysis Outcomes and Practice Patterns Study (DOPPS). PLoS Med. 2014;11(10): e1001750.

31. van Blijderveen JC, Straus SM, Zietse R, Stricker BH, Sturkenboom $\mathrm{MC}$, Verhamme KM. A population-based study on the prevalence and incidence of chronic kidney disease in the Netherlands. Int Urol Nephrol. 2014;46(3):583-592.

32. Stanifer JW, Jing B, Tolan S, et al. The epidemiology of chronic kidney disease in sub-Saharan Africa: a systematic review and meta-analysis. Lancet Glob Health. 2014;2(3):e174-e181.

\section{Publish your work in this journal}

The International Journal of Nephrology and Renovascular Disease is an international, peer-reviewed open access journal focusing on the pathophysiology of the kidney and vascular supply. Epidemiology, screening, diagnosis, and treatment interventions are covered as well as basic science, biochemical and immunological studies. The manuscript management system is completely online and includes a very quick and fair peer-review system, which is all easy to use. Visit http://www. dovepress.com/testimonials.php to read real quotes from published authors. 